\title{
Prototecose cutânea: relato de caso
}

\author{
Cutaneous protothecosis: case report
}

\author{
Fabiana Pirani Carneiro ${ }^{1}$, Mário Augusto P. Moraes ${ }^{1}$, \\ Ana Maria G. Rebêlo ${ }^{1}$ e Amália M. Coutinho ${ }^{2}$
}

\begin{abstract}
RESUMO
Descreve-se um caso de prototecose cutânea em paciente de 78 anos, submetido a tratamento para pênfigo foliáceo e feohifomicose. Ele apresentava lesões eritematosas infiltradas na perna direita e o diagnóstico foi feito através de estudo histológico e através de cultura da pele lesada. A cura foi obtida com o uso oral de itraconazol.
\end{abstract}

Palavras-chaves: Prototecose. Feohifomicose. Itraconazol. Alga.

\begin{abstract}
A case of cutaneous protothecosis was reported in a 78-year-old man that was in treatment for pemphigus foliaceus and phaeohyphomycosis. He presented erythematous lesions which were infiltrated into his right leg. The diagnosis was made histopathologically and confirmed by culture, and the patient was successfully treated with itraconazole.
\end{abstract}

Key-words: Protothecosis. Phaeohyphomycosis. Itraconazole. Algae.

Prototecose é uma infecção rara, causada por algas do gênero Prototheca, na maioria dos casos, por Prototheca wickerhamii, espécie que acomete o homem e outros animais. Em humanos, há cerca de 100 casos descritos no mundo, sendo cinco deles no Brasil ${ }^{158916}$. É considerada infecção oportunística, acometendo principalmente indivíduos com alguma forma de imunocomprometimento ${ }^{11} 1314$. Acredita-se que a transmissão ocorra por inoculação traumática e contato com solo ou água contaminados $^{6}$. São observadas principalmente três formas da doença, a cutânea, a articular e a sistêmica. A cutânea é a mais comum; as lesões ocorrem predominantemente em áreas expostas e podem ser de vários tipos: pápulas, nódulos, placas, úlceras etc ${ }^{2}$. Não há consenso sobre o tratamento, sendo muito utilizados os antifúngicos sistêmicos ${ }^{7}$. É considerada uma doença pouco diagnosticada por ser mal conhecida e deve ser diferenciada de outras doenças, principalmente, infecções fúngicas. Nesse sentido, nosso objetivo é relatar um caso de prototecose cutânea humana, o sexto caso descrito no Brasil.

\section{RELATO DO CASO}

Paciente do sexo masculino, 78 anos, trabalhador rural aposentado e procedente do Recanto das Emas (DF). Em fevereiro de 2006, foi encaminhado ao ambulatório de dermatologia do
Hospital Universitário de Brasília (HUB) com o diagnóstico de pênfigo foliáceo, dado em outro serviço; estava, por isso, em uso crônico de prednisona $(60 \mathrm{mg} /$ dia inicialmente e depois $40 \mathrm{mg} / \mathrm{dia}$ ) havia dois anos. Apresentava ele também, havia dois meses, massa violácea, firme, bem delimitada em dorso da mão e punho direitos, medindo $8 \mathrm{~cm} \times 6 \mathrm{~cm}$, na qual foi realizada biópsia para exame histopatológico e cultura. Ao exame histológico, o achado foi de processo inflamatório granulomatoso e supurativo, com hifas e corpos redondos pigmentados, compatível com feohifomicose, diagnóstico este confirmado pela cultura sendo isolado o fungo Exophiala jeanselmei. Foi instituído tratamento com itraconazol (200mg, duas vezes ao dia) e fez-se a retirada gradual do corticóide. Em maio de 2006, o paciente procurou 0 hospital relatando que as lesões na mão não haviam regredido e que surgiram também lesões no membro inferior direito. 0 quadro clínico era de erisipela acompanhada por pápulas, bolhas e lesões nodulares (Figura 1). Foi então realizada biopsia em uma das lesões elevadas e enviado material para exame histopatológico e cultura. Ao exame histológico observaram-se focos de processo inflamatório granulomatoso em torno de estruturas arredondadas (Figura 2), algumas com endosporulação e aspecto de mórula (Figura 3), positivas nas colorações especiais para fungos - PAS (ácido periódico Schiff) e Grocott. 0 quadro histológico era sugestivo de prototecose e esse diagnóstico foi confirmado pela cultura. Em meio de Sabouraud, foram observadas colônias

1. Centro de Anatomia Patológica, Hospital Universitário de Brasília, Brasília DF. 2. Serviço de Dermatologia, Hospital Universitário de Brasília, Brasília DF. Endereço para correspondência: Dra. Fabiana Pirani Carneiro. Centro de Anatomia Patológica. HUB/UnB. Via L2 Norte, SGAN 604/605, Módulo C, 70840-050 Brasília, DF. Tel: 556134485499

e-mail: fabianapirani@hotmail.com

Recebido em: 01/03/2007

Aceito em: 12/07/2007 


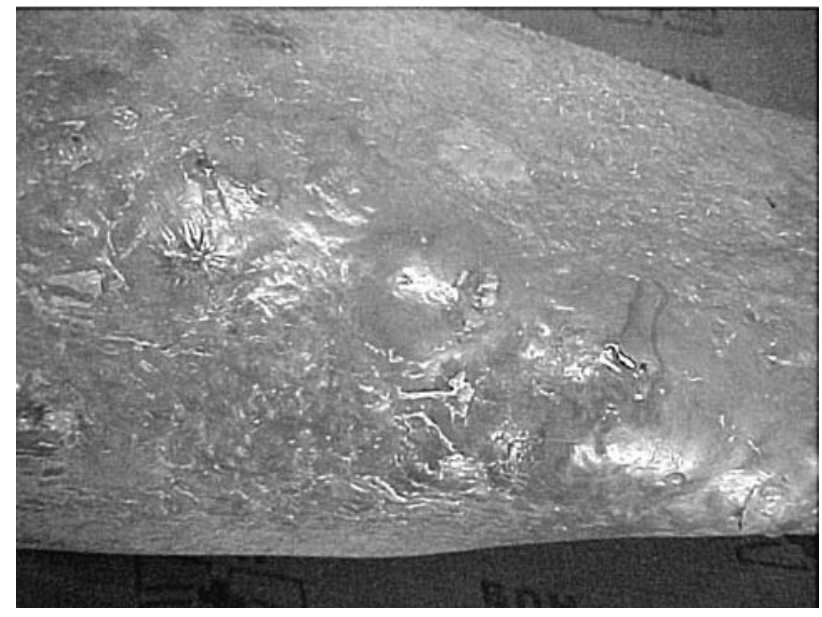

Figura 1 - Lesões eritematosas infiltradas na perna.

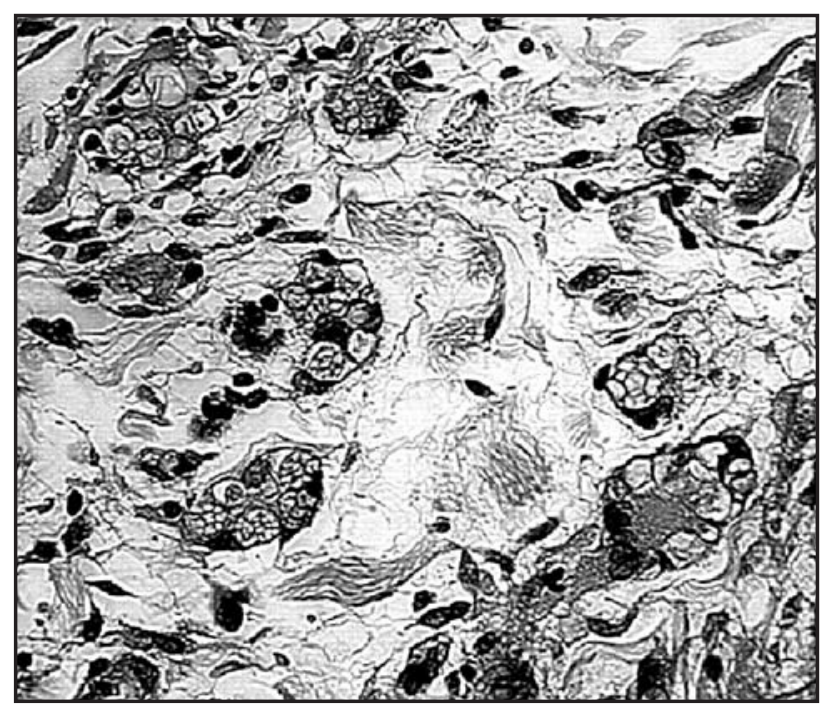

Figura 2 - Estruturas arredondadas dispostas em pequenos grupos na derme. $\mathrm{HE} ; 200 \mathrm{X}$.

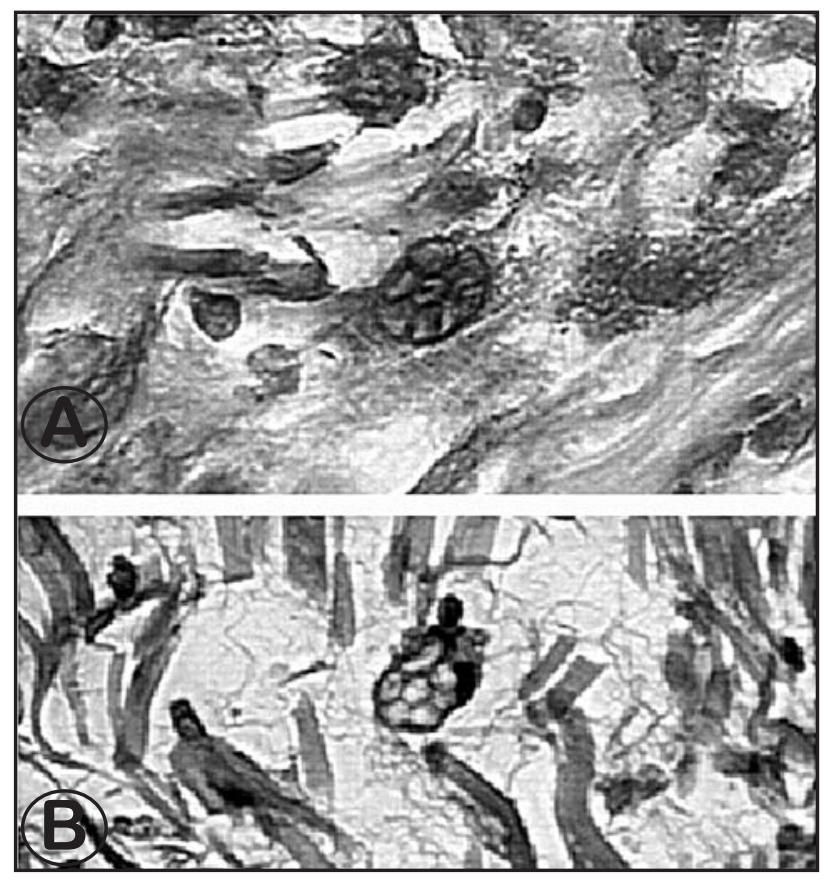

Figura 3 - Aspecto de mórula típico. Em A HE, 400X; em B PAS, 400X. brancas cremosas, leveduriformes cujo exame microscópico mostrou esférulas com múltiplos endósporos no interior e 0 aspecto de mórula, compatível com Prototheca sp (Figura 4). Pela morfologia e testes de assimilação dos açúcares, identificou-se a espécie como Prototheca wicherhamii. Foi então introduzida antibioticoterapia para 0 tratamento da erisipela e mantido 0 itraconazol por 6 meses para a feohifomicose e prototecose, quando então se obteve melhora do quadro.

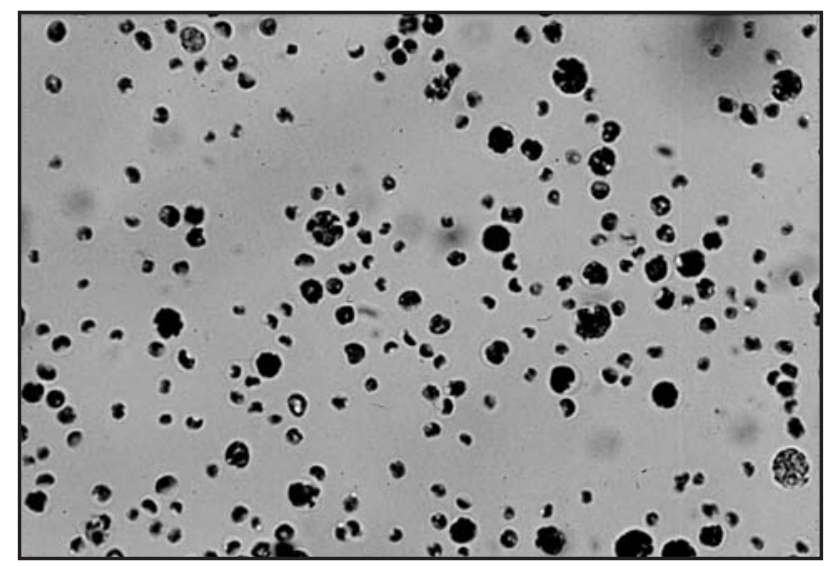

Figura 4 - Material proveniente da cultura da pele lesada mostrando esférulas com endósporos no seu interior (400X).

\section{DISCUSSÃo}

No caso acima descrito, assim como em outros publicados previamente ${ }^{11314}$, o paciente apresentava certo grau de imunocomprometimento (história de uso crônico de corticóide oral), fator que pode não só ter favorecido a infecção pela alga, mas também a infecção pelo fungo. Não havia relato de trauma no local da lesão, mas é possível que a pele previamente lesada pela erisipela tenha contribuído para a implantação da prototeca.

Quando não diagnosticada, a prototecose pode produzir lesões crônicas destrutivas e, no presente caso, assim como em relatos anteriores, não havia suspeita clínica ${ }^{312}$. 0 diagnóstico foi realizado pelo exame histológico e pela cultura da pele lesada, os quais identificaram a alga. Nos tecidos e na cultura, essas algas se apresentam como esférulas de 3 a $30 \mu \mathrm{m}$ e com 2 a 20 endósporos no seu interior ${ }^{10}$, algumas com 0 aspecto de mórula, isto é, com um endósporo central envolvido por vários endósporos ${ }^{15}$. No exame histológico, o principal diagnóstico diferencial é com infecções fúngicas. Isso porque nos tecidos alguns tipos de fungos podem apresentar aspectos morfológicos semelhantes ao da prototeca e, além disso, as colorações especiais para fungos também coram a alga. Na coccidioidomicose, histologicamente, os fungos também apresentam-se como esférulas com endósporos em seu interior. Contudo, essas esférulas são maiores $(20$ a $200 \mu \mathrm{m})$ e contêm maior número de endósporos ${ }^{10}$. Na cultura, esses fungos, como são dimorfos, crescem sob forma filamentosa e produzem artroconídios; podem assim ser diferenciados das prototecas ${ }^{4}$.

Quanto ao tratamento, segundo alguns autores, os imidazólicos seriam mais indicados para doença localizada. Entre eles, 0 itraconazol parece ser 0 agente mais efetivo e deve 
ser administrado na dose de $200 \mathrm{mg} /$ dia por dois meses 7 . Em nosso caso, quando surgiram as lesões da prototeca, o paciente já vinha em uso domiciliar de itraconazol para a infecção fúngica e, mesmo assim, desenvolveu a prototecose e não apresentou melhora da lesão fúngica. Isso pode ser explicado pelo uso irregular do medicamento, que foi relatado pelo próprio paciente. Após o aparecimento da erisipela e da prototecose, o paciente foi internado para tratamento e as lesões começaram a regredir.

\section{REFERÊNCIAS}

1. Agostini AA, Lisot JMC, Gonzales DHV. Prototecose do cotovelo: relato de um caso. Revista da Associação Médica Brasileira 29:178-179, 1983.

2. Boyd AS, Langley M, King Jr LE. Cutaneous manifestations of Prototheca infections. Journal of the American Academy of Dermatology 32:758-764, 1995.

3. Chao SC, Hsu MM, Lee JY. Cutaneous protothecosis: report of five cases. British Journal of Dermatology 146:688-693, 2002.

4. DiCaudo DJ. Coccidioidomycosis: a review and update. Journal of the American Academy of Dermatology 55:929-942, 2006.

5. Follador I, Bittencourt A, Duran F, Araujo MG. Cutaneous protothecosis: report of the second Brazilian case. Revista do Instituto de Medicina Tropical de São Paulo 43:287-290, 2001

6. Huerre M, Ravisse P, Solomon H, Ave P, Briquelet N, Maurin S, Wuscher N. Human protothecosis and environment. Bulletin of the Exotic Pathology Society 86: 484-488, 1993
7. Kantrow SM, Boyd AS. Protothecosis. Dermatologic Clinics 21:249-255, 2003

8. Leimann BC, Monteiro PC, Lazera M, Candanoza ER, Wanke B. Protothecosis. Medical Mycology 42:95-106, 2004.

9. Muramatu LH, Arrigada GL, Heins-Vaccari EM, Martins JE. Cutaneous protothecosis: report of a third Brazilian case. International Journal of Dermatology 45:124-126, 2006.

10. Pfaller MA, Diekema DJ. Unusual fungal and pseudofungal infections of humans. Journal of Clinical Microbiology 43:1495-1504, 2005.

11. Piyophirapong S, Linpiyawan R, Mahaisavariya $\mathrm{P}$, Muanprasat C, Chaiprasert A, Suthipinittharm P. Cutaneous protothecosis in an AIDS patient. British Journal of Dermatology 146:713-715, 2006.

12. Schumann K, Hollandsworth K, Ormsby A. Nonhealing legulceration. Diagnosis: protothecosis. Archives of Dermatology 136:1263-1268, 2000.

13. Torres HA, Bodey GP, Tarrand JJ, Kontoyiannis DP. Protothecosis in patients with cancer: case series and literature review. Clinical Microbiology and Infection 9:786-792, 2003.

14. Tsuji K, Hirohara J, Fukui Y, Fujinami S, Shiozaki Y, Inoue K, Uoi M, Hosokawa H, Asada Y, Toyazaki N. Protothecosis in a patient with systemic lupus erythematosus. Internal Medicine 32:540-542, 1993.

15. Walsh SV, Johnson RA, Tahan SR. Protothecosis: an unusual cause of chronic subcutaneous and soft tissue infection. American Journal of Dermatopathology 20:379- 382, 1998.

16. Zaitz C, Miranda Godoy A, Sousa VM, Ruiz LR, Masada AS, Nobre MV, Santos AR, Marques AC, Muramatu LH, Arrigada GL, Heins-Vaccari EM, Martins JE. Onychoprotothecosis: report of the first case in Brazil. International Journal of Dermatology 45:1071-1073, 2006. 